archives-ouvertes

\title{
Digital inequalities 2.0: Legacy inequalities in the information age
}

Laura Robinson, Jeremy Schulz, Grant Blank, Massimo Ragnedda, Hiroshi

Ono, Bernie Hogan, Gustavo Mesch, Shelia Cotten, Susan Kretchmer, Timothy Hale, et al.

\section{To cite this version:}

Laura Robinson, Jeremy Schulz, Grant Blank, Massimo Ragnedda, Hiroshi Ono, et al.. Digital inequalities 2.0: Legacy inequalities in the information age. First Monday, University of Illinois at Chicago Library, 2020, 25 (7), 10.5210/fm.v25i7.10842 . halshs-02889893

\section{HAL Id: halshs-02889893 https://halshs.archives-ouvertes.fr/halshs-02889893}

Submitted on 5 Jul 2020

HAL is a multi-disciplinary open access archive for the deposit and dissemination of scientific research documents, whether they are published or not. The documents may come from teaching and research institutions in France or abroad, or from public or private research centers.
L'archive ouverte pluridisciplinaire HAL, est destinée au dépôt et à la diffusion de documents scientifiques de niveau recherche, publiés ou non, émanant des établissements d'enseignement et de recherche français ou étrangers, des laboratoires publics ou privés. 


\title{
Digital inequalities 2.0: Legacy inequalities in the information age
}

Laura Robinson, Jeremy Schulz, Grant Blank, Massimo Ragnedda, Hiroshi Ono, Bernie Hogan, Gustavo Mesch, Shelia R. Cotten, Susan B. Kretchmer, Timothy M. Hale, Tomasz Drabowicz, Pu Yan, Barry Wellman, Molly-Gloria Harper, Anabel Quan-Haase, Hopeton S. Dunn, Antonio A. Casilli, Paola Tubaro, Rod Carveth, Wenhong Chen, Julie B. Wiest, Matías Dodel, Michael J. Stern, Christopher Ball, Kuo-Ting Huang, and Aneka Khilnani.

First Monday, Volume 25, Number 7 - 6 July 2020

https://journals.uic.edu/ojs/index.php/fm/article/download/10842/9561

doi: http://dx.doi.org/10.5210/fm.v25i7.10842

\begin{abstract}
2020 marks the 25th anniversary of the "digital divide." Although a quarter century has passed, legacy digital inequalities continue, and emergent digital inequalities are proliferating. Many of the initial schisms identified in 1995 are still relevant today. Twenty-five years later, foundational access inequalities continue to separate the digital haves and the digital have-nots within and across countries. In addition, even ubiquitous-access populations are riven with skill inequalities and differentiated usage. Indeed, legacy digital inequalities persist vis-à-vis economic class, gender, sexuality, race and ethnicity, aging, disability, healthcare, education, rural residency, networks, and global geographies. At the same time, emergent forms of inequality now appear alongside legacy inequalities such that notions of digital inequalities must be continually expanded to become more nuanced. We capture the increasingly complex and interrelated nature of digital inequalities by introducing the concept of the "digital inequality stack." The concept of the digital inequality stack encompasses access to connectivity networks, devices, and software, as well as collective access to network infrastructure. Other layers of the digital inequality stack include differentiated use and consumption, literacies and skills, production and programming, etc. When inequality exists at foundational layers of the digital inequality stack, this often translates into inequalities at higher levels. As we show across these many thematic foci, layers in the digital inequality stack may move in tandem with one another such that all layers of the digital inequality stack reinforce disadvantage.
\end{abstract}

\section{Introducing legacy inequalities in the information age: The digital inequality stack}

2020 marks the $25^{\text {th }}$ anniversary of the "digital divide". This important milestone is marked in First Monday through a two-article series on digital inequalities in a special section bringing together scholars from across the globe whose expertise and vision have evolved with the very field itself. Despite the passing of a quarter century, legacy digital inequalities remain, while emergent digital inequalities are proliferating.

In the first article, "Digital inequalities 2.0: Legacy inequalities in the information age," we observe that many of the initial schisms identified in 1995 are still relevant today [1]. Twenty-five years later, foundational access inequalities continue to separate the digital-haves and the digital have-nots within and across countries. In addition, even in populations where access is widespread, there are distinct inequalities in terms of quality of network and device access. Further, even near ubiquitous-access populations are marked by differentiated usage and riven with skill divides. Indeed, legacy digital inequalities persist vis-à-vis economic class, gender, sexuality, race and ethnicity, aging, disability, healthcare, education, rural residency, networks, and global geographies - all of which are being exacerbated at the time of writing by the COVID-19 pandemic. 
At the same time, emergent forms of inequality continually appear alongside legacy inequalities. In the second article in this two-part series, "Digital inequalities 3.0: Emergent inequalities in the information age," we explicitly offer an enlarged vision of digital inequalities to advocate for broadband accessibility as a human right. We examine the increasingly complex inequalities spawned by the platform economy, digital labor, automation, big data, the use of algorithms in the criminal justice system, cybersafety, civic engagement, mobility, gaming, well-being and the life course, and assistive technologies.

Across these two articles, we capture the increasingly complex and interrelated nature of digital inequalities by coining the term the "digital inequality stack." We draw our inspiration from the computing stack, which comprises multiple layers that must work together including the operating system, network, software, and user interface. We metaphorically extend the concept of the computing stack to capture the complexities of digital inequalities as they occur on many interrelated levels. When we transform the metaphor to speak to digital inequalities, we see that layers include access, skills, and usage - all of which must work in concert for optimal outcomes.

Concerning the access layer of the digital inequality stack, the concept of access must capture connectivity, device, and software access. Connectivity inequalities exist in terms of quality, duration, continuity, etc. In addition, device inequalities exist independent of connectivity. Highly resourced individuals enjoy a portfolio of multiple devices appropriate to different usage and tasks for their personal use such that they have mobile, atwill access 24/7. A third facet of access accounts for software, applications, cybersecurity, and other paid services; those with fewer resources may not have access to paid services they cannot afford from Office subscriptions to anti-virus software to name but two examples.

In addition, connectivity, device, and software access inequalities, skills and usage are also heterogeneous. From diverse domains of consumption from information seeking to shopping, differentiated use and skills continue to manifest themselves. Skill and usage inequalities also encompass prosumption activities including social media production and curation, rating systems, etc. At the production end of the spectrum, skill inequalities also exist from programming to software design to hardware engineering to Al and beyond. Skills may also impact usage and vice versa, particularly for capital-enhancing activities. Obvious examples include telework, e-learning, and telemedicine that may act to replicate both digital advantage and disadvantage.

As we show across multiple contexts, the concept of the digital inequality stack is central to legacy and emergent forms of inequality in the digital age. The digital inequality stack's infrastructure layer necessitates collective access to network infrastructure, as well as individual access to devices. Other layers of the digital inequality stack include opportunities for literacy acquisition and skill building, all of which are implicated in differentiated use, consumption, production, etc. While foundational layers are necessary, they are insufficient to automatically enable higher layers. Therefore, as we show, it is a grave error to believe that universal access and mobility automatically or organically obviate higher level divides such as skills and literacies. On the contrary, as ubiquitous mobile computing and connectivity evolve, each new wave of "progress" simultaneously generates new avenues for the reproduction of disparities. Therefore, social inequalities are continually being amplified and reproduced in the digital realm, ever necessitating a fresh examination of the field.

\section{From digital divides to digital inclusion}

Research on the digital divide has three generally recognized topics: access, use, and outcomes. These correspond roughly to three time periods of research. The first-level digital divide refers to physical access to computers and the Internet. This was the sense in which the term "digital divide" was first used in a report published in 1995 by the National Telecommunications and Information Administration (NTIA) titled "Falling through the Net: A survey of the "have nots' in rural and urban America." This report initiated a research stream that understood the digital divide in largely technical terms about who had and did not have access to necessary hardware (Katz and Aspden, 1997; Hoffman and Novak, 1998). Much of this work analyzed demographic predictors of Internet access.

Access alone suggests a techno-deterministic perspective where the benefits of a technology automatically follow adoption, but the Internet is complex and not easy to navigate. Simply because people who have Internet access does not mean they are all equally successful in their use of the Internet. Thus, the conceptual 
focus of research broadened to address the question of who makes effective use of digital technologies. This research stream is often called the "second-level divide" (Attewell, 2001), but it is also called the "participation gap" (Jenkins, et al., 2006), "emerging digital differentiation" (Peter and Valkenburg, 2006) or the "usage gap". These concepts highlight inequalities in participation based on digital skills, how the Internet was used, as well as demographic predictors.

Access, skills, and use also turn out not to be sufficient to characterize Internet use; they are inputs, and what we really care about are outcomes. This is the "third-level digital divide". The research questions here include what groups of people use the Internet to improve their learning, information-seeking, productivity, and other activities that enhance their income and influence as opposed to using the Internet for entertainment or sports. The consistent answer is that people from more privileged backgrounds tend to engage in more capitalenhancing activities (Bonfadelli, 2002; Eynon, 2009).

People on the wrong side of any of the digital divides - access, use, and outcomes - can be seriously disadvantaged. The digital advantaged have regular, reliable access to digital technologies without significant opportunity costs. As we will see, these digital resources provide them with opportunities across all life spheres from jobs, to health information, products and services, and education. Also as we will see, digital resources and skills are increasingly needed to participate as a digital citizen and to protect against harmful outcomes, such as ransomware or credit card fraud. For all of these reasons, from the macro-perspective, as countries become more digital-intensive, digital resources are increasingly vital to enhance economic productivity, social inclusion, and efficient government services. In this way, digital inequality has implications for the economic, social, and political well-being of whole countries.

\section{Economic class}

Economic class remains a strong predictor of disparities throughout the digital inequality stack, including quality of hardware, software, network access, usage patterns, and skills. In 2019, even as certain populations approach ubiquitous adoption, those on the bottom rungs of the economic ladder are far more likely to be partially or wholly digitally excluded than those on higher rungs of the economic class ladder. For example, even in countries with the highest levels of Internet adoption and digital device diffusion such as the Netherlands, there is still a statistically significant income gradient in relation to access, use, and diversity of digital devices (van Deursen and van Dijk, 2019).

In the U.S., Pew data reveals striking differences are obvious between Americans earning less than $\$ 30,000$ per year and those earning more than $\$ 100,000$ per year. More specifically: 1) 29 percent of low-income Americans compared to three percent of high-income Americans do not own smartphones; 2) 44 percent of low-income Americans compared to six percent of high-income Americans do not have broadband service; 3) 46 percent of low-income Americans compared to six percent of high-income Americans do not have a laptop or desktop computer; 4) 64 percent of low-income Americans compared to 30 percent of high-income Americans do not own a tablet; and, 5) 18 percent of low-income Americans compared to 64 percent of high-income Americans own all of these digital devices and services (Anderson and Kumar, 2019).

Further, disparities exist in usage patterns and digital footprints associated with economic class that have strong implications for life chances. They argue that those occupying already privileged economic positions in society have higher-quality access to digital resources, use those resources more profitably and effectively, and further enhance their economic well-being. More specifically, those who are from higher economic status groups are more likely to use the Internet for work (Selwyn, 2005), for capital-enhancing activities (DiMaggio, et al., 2004), for education (Robinson and Schulz, 2013), for healthcare (Khilnani, et al., 2020) and to reinforce their social position in society (van Deursen and van Dijk, 2014). In sum, the economically privileged use the Internet more broadly and in more sophisticated ways for informational or service-oriented purposes than their lower income counterparts who are more likely to use digital resources for entertainment (Bonfadelli, 2002; Peter and Valkenburg, 2006).

Economic class also influences levels of digital capital (Ragnedda, et al., 2020) and the capacity to gain greater benefits from the use of the Internet (Ragnedda, 2018, 2017). The Matthew effect (Merton, 1968), the knowledge gap (Tichenor, et al., 1970) and the accumulation of advantage hypothesis help explain the relationship between economic advantage and multiple layers of the digital inequality stack. 


\section{Gender}

Gender represents a particularly interesting case of how disparities cut across multiple layers of the digital inequality stack. Research has shown that the diffusion of the Internet followed conventional trajectories by spreading unevenly along existing axes of social inequality, especially in its early stages (Norris, 2001; Ono and Zavodny, 2007). Gender differences in online activity were a key focal point in the first wave of digital inequality research, arising out of concerns that women may have less access to the Internet, and consequently be excluded from reaping the benefits of the information economy. Subsequent waves of research established that, at least in the U.S. and other advanced economies, the gender gap in access and use had disappeared, or had even reversed (Campos-Castillo, 2015; Ono and Zavodny, 2003).

Recent research on gender and digital inequality has evolved from simply identifying and monitoring gender gaps in Internet use, to more in-depth and nuanced studies that explore emerging themes related to digital activities. Studies of Internet addiction, for example, typically show that men are more prone to Internet addiction than are women (Kannan, et al., 2019). The gender gap in cybercrime is another emerging issue. Reflecting the general trend that men are more likely to engage in offending behavior than are women, Donner (2016) finds that male undergraduate students report higher rates of digital piracy, cyber-harassment, and hacking than do their female counterparts. Other studies have examined gender differences in cyber-loafing (Baturay and Toker, 2015), Internet affairs and infidelity, the use of online versus printed newspapers (Taipale, 2013), as well as the use of online and off-line identities (Helsper, 2014).

Current research has also put the spotlight on the gender gaps that still remain in emerging countries. Significantly, for sociologists, these studies remind us that context matters: women in emerging countries have less access because of differences in social norms, expectations, and institutional arrangements. Examples include Bertrand and Fidele's (2016) study of Internet adoption in Cameroon; Gray, et al.'s (2017) study of Internet use in Latin American countries; and, Hoque, et al.'s (2017) study of e-Health adoption in Bangladesh.

The Organisation for Economic Cooperation and Development (OECD) published Bridging the digital gender divide (OECD, 2018) which called attention to the widening gender gap in Internet usage among the emerging countries. Between 2013 and 2017, the gender gap narrowed in developed economies, whereas it widened in less developed countries. The report outlines the vicious cycle, particularly in the emerging countries, where women are less likely to have access to the Internet and other digital technologies, which in turn lowers their likelihood of participation in labor markets and socio-economic advancement as a whole, which ultimately lowers the educational aspirations of women for the subsequent generations. The report calls for specific action plans such as integrating digital technologies to compulsory education and raising awareness about online education programs (e.g., MOOCs). Finally, while gender and digital inequalities have been studied as a binary distinction between men and women, future research may reflect the evolution of more diverse gender categories.

\section{Sexuality}

Sexuality has implications for the digital inequality stack vis-à-vis second- and third-level digital inequalities. Whether online or off-line, sexuality concerns the expression of human desire for intimate companionship. Humans have a vast array of sexual expressions and orientations that reflect a seemingly limitless array of desires and interests beyond functional pro-creation. The Internet reconfigures accessibility and other forms of digital resource inequality (Dutton, et al., 2009). This reconfiguration has implications for members of sexual minorities.

On coming out: The online world has a tendency to collapse contexts into consolidated "newsfeeds" and unitary real-name identities (Duguay, 2016). Those who come out have different friendship patterns online (McConnell, et al., 2018) and different impression management strategies (Szulc and Dhoest, 2013). Through groups, forums, pages, and chat rooms, the Internet has revealed and consolidated a variety of new communities, often around paraphilias [i.e., fetishes] such as "furry," "bear," "adult baby," "pup," etc. (McNair, 2013). With the heightened visibility and prevalence of paraphilias, coming out can be even more complex. For 
example, one might doubly come out as gay and a chubby chaser (Rosenmann and Safir, 2006). This is in addition to the challenges of coming out alongside other intersectional issues with self presentation online including but not limited to race, ethnicity, sexuality, and economic class (McConnell, et al., 2018).

The digital world can make sexual minorities vulnerable in terms of forced disclosure and privacy, as well as the risks of bullying. This is true of online dating. Reconfiguring access means people and sexual objects are more findable and yet more vulnerable to the gaze of others, potentially disempowering individuals in terms of public stigma such as "slut shaming" and complicating relationship formation and dissolution (Gershon, 2010; Hogan, 2018). For gay men, the mobile app Grindr was a paradigm shift in findability (Blackwell, et al., 2015) potentially narrowing the opportunity for finding relationships in the physical world while providing less satisfying digital alternatives.

Whereas disconnecting from commercial platforms can be seen as a way out in some cases, complete isolation from these platforms is hardly a feasible solution given the depth and extension to which women establish and maintain connections through them. Indeed, responsibility in and for the worldings in play on the Web requires the cultivation of response-abilities, instead of evasion when facing violent attacks. This means embedding infrastructural meanings and materials into our engagement with technology (e.g., autonomous servers, hashtags), to infect technological processes and practices, compose and assemble shared stories from a feminist perspective - a kind of situated worlding. The examples we have discussed indicate the multiple ways through which women can get involved in online progressive politics: while some aim at recoding the unequal and misogynist infrastructure of the Web, some navigate and appropriate the space provided by commercial platforms.

Further, the shift to the digital creates hidden inequalities given the prevalence of dating sites and social media content data that reproduces or even exaggerates traditional sexual norms. Researchers have shown the existence of desire hierarchies on online dating sites (Bruch and Newman, 2018), while others have begun documenting the emergence of (often misogynistic) sexual grievance cultures such as the men's rights movement (LaViolette and Hogan, 2019). Internet infidelity also emerges as it is easy to slide across boundaries online that would be otherwise clearly demarcated in off-line interaction (Norton, et al., 2018) with sites such as AshleyMadison.com.

The fact that digital images can be easily created and manipulated, for example, through pornography and deep fake, make some demographic groups more vulnerable than others. But regulating access to pornography has proven difficult despite strong motivation from the challenges Internet porn creates or exacerbates. Stigma around nudity/sexuality coupled with easy access has led to concerns with "revenge porn" (Bates, 2017), "human flesh search"/facial recognition (Chao and Tao, 2012), and more recently "deep fakes". These put sexual minorities and women at additional risk, particularly as women are more likely than men to be victims (Bates, 2017). Reports of child pornography are exploding while unwanted or unexpected exposure to pornography among pubescent/pre-pubescent children remains alarmingly high (Livingstone, et al., 2018). Finally, compulsive pornography use is facilitated by the Internet and overuse of pornography is associated with lower relationship satisfaction (Morgan, 2011) although meta-analyses suggest these findings might be overstated.

\section{Race and ethnicity}

With respect to inequalities related to race and ethnicity, the digital inequality stack plays out differently across global contexts. Digital inequalities often augment racial and ethnic disparities that intersect with other forms of inequality (Fuchs and Horak, 2008) as in the case of multicultural societies that are characterized by the existence of ethnic and racial groups that hold different positions in the stratification system.

The study of digital inequality investigates how different ethnic and racial groups access and use new technology and how their differing digital engagements lead to the amplification or reduction of social disadvantages (Chen, 2013). For example, it is well documented that because of health-related social inequalities, minorities are more likely to access online health information but less likely to use e-health services (Mesch, et al., 2012; Mesch, 2016; Mitchell, et al., 2019), a service that is essential during the ongoing COVID-19 pandemic (Khilnani, et al., 2020). As this indicates, digital resources may both reinforce existing racial inequalities or provide new avenues through which some inequalities may be mitigated. Reflecting this tension, 
research on digital inequalities has relied on two central contrasting perspectives in relation to race and ethnicity: the stratification hypothesis and the diversification hypothesis.

The stratification hypothesis holds that the process of ICT adoption, use, and skills, replicates existing social inequalities, and online networks replicate off-line social network structures. Early research showed that Internet use among ethnic and racial minorities was typically lower among racial minority groups than for majority groups. Disadvantaged minorities in the U.S. have smaller social networks and greater network homophily, representing a barrier for access to social capital (DiMaggio and Garip, 2012; DiPrete, et al., 2011). According to the stratification hypothesis, as with gender, these early studies indicated that digital inequalities related to race and ethnicity followed the trajectories of off-line marginalization.

By contrast, the diversification hypothesis holds that ethnic and racial groups can expand their social networks and social capital through access to online networks. Consistent with this perspective, studies in the U.S. found that African Americans reported a significantly higher number of weak ties, while White Americans had a significantly higher number of strong ties. Work on Brazil among "Afro-Brasileiros" in low-SES neighborhoods also shows how digital resources can be employed to cross social boundaries and forge beneficial ties (Nemer, 2015). Minorities' efforts are directed to access information and resources through weak ties, consistent with the social diversification hypothesis (Mesch, 2018). These theoretical perspectives are not incompatible. While the stratification hypothesis is better suited to the study of social inequality in access, the social diversification hypothesis is more suited for the study of the outcomes of access and use.

Minorities may use ICT to reduce network homophily and increase the number of weak ties to others. Thus, social media may constitute a promising ICT-based mechanism for the reduction of inequalities by creating weak ties which translate into real changes in social capital. Another example is the utilization of social media for content creation in the U.S. where African Americans report more online content creation than comparable European Americans. These preliminary results call for moving a step forward and investigating the extent to which activities such as content creation and the use of social media could potentially enhance the social capital of minority users.

\section{Aging}

Like other segments of the population, older adults also exhibit disparities associated with access, usage, and skills. In addition to these facets of the digital inequality stack, they are more likely to encounter challenges with technostress and technology maintenance. Although the proportion of older adults who are digitally active is increasing, individuals aged 65 and older are a heterogeneous demographic group, with significant differences in ICT use, exposure, and impacts. Compared to younger age groups, individuals aged 65 and older are still less likely to use the Internet, smartphones, and social media (Anderson and Kumar, 2019; Anderson and Perrin, 2017). Individuals aged 80 and older are even less likely to use ICTs than are those aged 65-79.

For those who are able to go online and use ICTs, this provides them opportunities to overcome spatial and social barriers, connect with social ties through e-mail, online communities, social media, and messaging, and access information for health, travel, entertainment, and other activities (Cotten, 2001; Cotten and Gupta, 2004; Hale, et al., 2018; Hale, et al., 2014). Staying engaged with social ties, participating in community events, and having access to informational and emotional resources are all critical to successful aging for older adults.

However, cost, cognitive ability, digital skills, and availability of technical support all factor into whether older adults (1) use ICTs; (2) continue to use ICTs over time; and, (3) acquire benefits of ICT use, particularly for individuals aged 80 and older (Cotten, et al., 2017; van Deursen and Helsper, 2015). Declining health and limitations in activities of daily living may also result in older adults who use ICTs not being able to maintain ICT use over time (Cotten, et al., 2017; Berkowsky, et al., 2015).

Maintenance of ICTs is particularly important for ensuring that older adults have continuous, quality access to digital resources and garner benefits from them (Cotten, forthcoming). When a device ceases to function as it should, ICT maintenance is difficult for many older adults and especially older adults of lower socioeconomic status. Low-SES older adults may lack either the financial means to pay the professionals, such as the Geek Squad, or the social ties to enlist help (Francis, et al., 2018). 
Finally, some older adults also experience technostress due to challenges associated with rapidly changing ICTs (Nimrod, 2018; Tarafdar, et al., 2007). Significant challenges for older adults include managing passwords, maintaining online safety, and understanding changing ICT interfaces (Cotten, Forthcoming; Cotten, et al., 2017; Jiang, et al., 2016). In sum, disparities in digital resources impact all layers of the digital inequality stack, especially for older adults who are also at risk for loss of digital autonomy and accompanying diminished wellbeing.

\section{Disability}

An understudied component of the digital inequality stack is disability. One of the most significant worldwide challenges for equality in the digital age is disability. One billion people, or 15 percent of the world's population are disabled. Those with disabilities, "Persons with disabilities are more likely to experience adverse socioeconomic outcomes than persons without disabilities, such as less education, poorer health outcomes, lower levels of employment, and higher poverty rates" (World Bank, 2020).

In terms of Internet (non-) use by various demographic groups in the U.S., the disability digital divide, as this aspect of digital inequality is known, is one of the largest and the most intractable. In 2017, the latest year for which data are available, the gap between non-disabled and disabled Internet users was 20.7 points. The disability digital divide has narrowed the least over time, when compared to other digital inequalities along demographic lines (U.S. Census Bureau, 2001-2017). Finally, disability intersects with other types of disadvantages in exacerbating digital inequality (Kretchmer and Drabowicz, 2018).

Recent research reveals the importance of the disaggregation of the disability digital divide by types of disability; how various demographic and socio-economic factors impact divergent groups differently; and the lack of relevance of the presence of home Internet service technologies on Internet use by those with most types of disabilities (Kretchmer and Drabowicz, 2018). Other research focuses on issues of assistive technologies, Web accessibility, usability, interoperability, and legal aspects (e.g., Blanck, 2014; Jaeger, 2011).

\section{Healthcare}

At first glance, it might appear that healthcare is less implicated in the digital inequality stack. The number and use of digital health technologies (DHTs) has expanded rapidly and are key components in strategies to improving healthcare and empowering people to achieve healthier lives (Kvedar, et al., 2014). Also termed "eHealth", DHT encompasses hardware and wearable devices, software, methods of data transmission and storage, and related technologies. The pace of DHT diffusion has increased dramatically in recent years. For example, mobile health apps have increased in number from 66,700 in 2013 to 318,600 in 2017 (Aitken, et al., 2017) and electronic health records (EHRs) are now in use in 84 percent of U.S. acute care hospitals in 2015, up from nine percent in 2008 (Henry, et al., 2016).

However, there is a growing realization that DHT benefits are not equally distributed, but vary by social factors (Fang, et al., 2019), thus indicating an important new layer in the digital inequality stack. In fact, new medical technologies do little to narrow social health disparities, as more advantaged populations (i.e., socio-economic status) are better positioned to take advantage of these new technologies (Phelan, et al., 2010). For this reason, although DHTs have the potential to improve care, their unequal use is creating new structural barriers to accessing health-related resources (Pérez-Stable, et al., 2019).

Therefore, recent DHT research has focused on how to overcome digital inequalities to ensure care equity and narrow gaps in social disparities in health (Fang, et al., 2019; Pérez-Stable, et al., 2019). Latulippe, et al. (2017) suggests a broader conceptualization of universal access, starting with physical access but also in creating DHT that meets the needs and preferences, skills, literacy level, and culture of future DHT users - particularly people from disadvantaged populations. Sociologists can make a significant contribution to the design of new, equitable DHTs via digital inequality research to understand how differences in access, use, skills, beliefs, and motivations of future DHT users vary by social factors. As with other layers of the digital inequality stack, the unequal ways that people use digital technology results in unequal benefits that derive from technology use, 
and subsequently, the reproduction of social inequalities (DiMaggio, et al., 2004) and potentially persistent social disparities in health (Fang, et al., 2019).

To narrow social disparities in health requires a different approach equalizing usage benefits by addressing all layers of the digital stack: access, use, skills, and orientations. A non-exhaustive list of promising strategies includes: (1) continuing research to understand barriers to access and use, especially as new DHTs are introduced and new digital inequalities emerge; (2) user-centered design; (3) health and numeracy literacy; (4) understanding the role of culture; (5) patient-provider communication and interaction; and, (6) communitybased, participatory research methods (Fang, et al., 2019; Latulippe, et al., 2017).

\section{Education}

As we have seen with many other legacy inequalities, educational disparities are implicated in every layer of the digital inequality stack. Scholars have begun to unpack the importance of access to digital resources and skill building in educational settings, as well as linkages to career training; both of which are vital for achievement. Students with insufficient access to digital resources are less likely to earn higher grades and benefit from skill-building opportunities in low-SES schools (Robinson, et al., 2018). Research also draws important connections between variations in access to digital resources and learning opportunities with emotional impacts and well-being (Huang, et al., 2015) that enhance students' desire to learn digital skills.

This being said, the overuse of digital technologies can be just as damaging to students' academic success as is insufficient access to digital resources (Gulek and Demirtas, 2005; Judge, 2005; Lei and Zhao, 2007). Further, academic performance as measured by grade point average implicates differentiated use of digital technologies (Cingel and Hargittai, 2018; Judge, et al., 2006; Junco and Cotten, 2012). Capital-enhancing activities are positively correlated with higher achievement, whereas elevated levels of social or leisure activities impede academic outcomes (Jackson, et al., 2008; Junco and Cotten, 2011).

Studies also indicate the importance of digital inequalities that impact career trajectories (Robinson, 2012). As the information economy transforms the numerous occupations, employers increasingly demand digital skills and literacies (Drabowicz, 2014). For many low-income students, school is the primary place where digital skills are acquired. Even in egalitarian countries such as Finland with excellent educational institutions, more than two thirds of Finnish adults with vocational education and training are at-risk or weak performers as regards digital skills (Hämäläinen, et al., 2015).

In turn, OECD research conducted in Germany on teenagers establishes that the old inequalities in the distribution of objectified cultural capital (Bourdieu, 1986) are being reproduced among teenagers with respect to new digital inequalities. More specifically, this research finds that even among students that can be classified as frequent digital users those living in a home with fewer traditional media sources tend to use digital technologies for leisure activities whereas those living in a home with plentiful traditional media sources tend to use digital technologies for academic activities (Drabowicz, 2017).

Finally, of critical importance, the occupational trajectories of digital workers are influenced by early educational experiences. While low-income youth have the most to gain by entering lucrative STEM professions, they are often the least likely to pursue STEM fields in college. STEM intent is positively associated with school-based and extracurricular enrichment activities as early as primary school (Moller, et al., 2015) and continues through early adolescence (Mahoney, 2010). Recent research probes the potential for digital resources in schools to slow the leakage from the STEM pipeline (Robinson, 2020) and builds upon scholars pioneering the use of gaming and VR experiences to bring low-income students into STEM careers (Ball, et al., 2018, 2017; Ball, et al., 2019).

\section{Rural and urban inequalities}

Rural-urban digital inequalities exist in both emerging and developed nations as another component of the digital inequality stack. For example, rural Internet users in the U.S. not only lack high-speed Internet 
infrastructure but also have lower adoption levels of Internet devices compared to urban users. The Oxford Internet Survey also suggests geographical inequality in Internet use in the U.K.

Meanwhile, due to the uneven distribution of ICT infrastructure, the rural-urban digital gap in emerging countries is wider than that of developed countries. In 2017, the Internet penetration rate in rural India was over 20 percent, which was almost 45 percent lower than that of urban India. The Internet penetration rate in rural China was just under 38 percent, which was over 36 percent lower than that of urban China.

Studies have shown that in addition to the rural-urban residence, the adoption of Internet services is also associated with other demographic factors such as age, education, and gender. As the Internet becomes the dominant source of everyday information-seeking for jobs, education, and business, structural constraints such as residence, education, and age have posed challenges for the digitally disadvantaged groups in rural areas.

To meet the challenges posed by inadequate infrastructure, leap-frogging mobile technologies have become widely used among rural populations. Oreglia (2015) studied the adoption and use of ICTs in rural and urban China and the role of migrant workers in giving mobile phones as gifts to their families in the village. She found that in rural China, ICTs are mainly used for leisure and maintaining social connections, not for information seeking about markets and farming techniques (Oreglia, 2013). Yu's (2010) study on information poverty also suggested that rural residents in China rarely use the Internet as a source of information.

Turning to potential solutions to rural digital inequalities, empirical studies have shown the effectiveness of interventions. Better quality Internet access and the provision of computer classes in rural areas mitigated rural-urban digital disparities in Taiwan. A macro-level study in China found that the introduction of mobile technologies halted the widening of gaps among Chinese provinces. Yet technology must be accompanied by skill-building opportunities. Local Chinese governments have played essential roles in providing training sessions for civil servants and setting up information centers that serve local farmers' agricultural needs. Thus, narrowing the rural-urban digital inequalities necessitates investment in infrastructure, the enhancement of digital skills, and improvement of information services.

\section{Networked individualism}

The digital inequality stack also has implications for network engagement and participation. Those who are unable to fully participate in digital networks are less likely to be networked individuals or individuals participating in multiple networks, each getting only their partial attention and commitment. Often, these are diverse networks of kin, friends, neighbors, and workmates (or schoolmates). Each may have only some connection with each other, and individuals have the freedom and the chore of maneuvering among them to find companionship, supportive resources, and information.

The concept of networked individualism describes people with partial membership in multiple, diversified networks who rely less on permanent membership in settled groups. Although most people in developed countries have local ties, the majority of their ties are not local (Fischer, 1982; Mok, et al., 2010). In these multiple, partial, often far-flung networks, people in different role relations provide specialized social support: for example, neighbors tend to exchange small services such as childminding while parents often provide financial aid. Networked individuals reach out in complex multiple networks - what Burt (2001) called "bridging capital" - that have relatively high contact with dissimilar others and diversified situations and ideas. Yet, not all ties are interacted with equally, as some partial networks are stronger, more diverse, and more densely knit than others (Quan-Haase, et al., 2018).

How has the turn to networked individualism come about? Although some form of networked individualism has been present for centuries, residents of the global north now live in network societies where formally organized institutions are less powerful than before (Castells, 1996). As women left home to do paid work, households became less like castles, and fluid work relationships superseded traditional jobs in large bureaucratic organizations. Moreover, the proliferation of instant mobile connectivity devices such as mobile phones and laptop computers have emphasized the individual rather than the household or the kinship unit as the hub for connectivity via the personally logged on Internet (Rainie and Wellman, 2012).

Such developments have afforded opportunities for those with digital resources to maintain ties over substantial distances and to rekindle them when they go fallow. They give resourced individuals more ability to 
reach into multiple social circles. Yet, to do so, individuals must network actively on their own rather than rest in the comfort of all-encompassing groups (Hampton and Wellman, 2018).

Not all residents of developed countries are networked individuals. Many continue to be members of traditional, encompassing groups in which they are embedded in a densely knit, relatively homogenous network of kin, neighbors, close friends, and social organizations. Members of such bounded networks gain in certainty of connectedness and collective efficacy while lack the information and resources coming from diverse sources. Moreover, despite the benefits of digital connectivity, still others continue to have only a limited number of neighborhood and kinship ties.

\section{Global digital inequality}

Numerous barriers to full inclusion exist at all layers of the digital inequality stack: affordability of devices and network services, inadequate infrastructure and institutions, digital literacy and skills gaps, and lack of supportive social networks. All of these challenges are magnified when combined with other inequalities. Therefore, we view the digital inequality stack from a global perspective, always acknowledging endemic inequalities within countries, as well as similarities and differences within regions.

Digital inequalities and divides between nations and regions of the world have long been of keen interest to scholars (Chen and Wellman, 2004). It is recognized that, in emerging countries, certain segments of the population are at the forefront of technology development and use equaling their elite counterparts in developed countries. Therefore, examining digital inequalities both within and across nations is important to shed light on how to understand global digital inequality and its consequences from micro and macro perspectives.

Probing the current state of global digital inequalities today, we see that legacy inequalities remain with us. Statistics from 2018 show that North America and Europe have the highest levels of Internet penetration, with 95 percent and 85 percent, respectively, which is in stark contrast to the 36 percent and 49 percent reported for Africa and Asia, respectively.

However, where traditional computing devices (laptops and desktops) are less widespread, mobile devices are surging. In these cases, technological leapfrogging via mobile devices has been a key factor in increasing rapid connectivity with the potential to create enhanced opportunities for connectivity, community, and economic gain (Ling and Horst, 2011). For example, while as much as three-quarters of the population in sub-Saharan Africa has a SIM connection, only a third of cell phone users can afford a smartphone (Radcliffe, 2018).

Researchers are seeking solutions to the low levels of Internet and smartphone penetration that undermine efforts to improve citizens' quality of life and increase participation in the global economy (Ragnedda and Muschert, 2013; Boas, et al., 2005). Key initiatives include ICT4D (Information and Communication Technology for Development), One Laptop per Child, and the UN 2030 Agenda. National communication solutions must include improvement of literacy levels, professional education, multi-stakeholder cooperation, appropriate and flexible regulation, and user-friendly access to governmental and institutional information. Finally, the unequal allocation of digital production and consumption must be one of the main foci of future digital inequality research. For example, given the rise in digitized labor, much of which is located in lower rungs of the economic value chain and is outsourced by developed to less developed regions, we may see digitization as an additional means to exploit cheaper labor. These and other social problems created by digital technologies are the new face of global digital inequality.

\section{Digital inequalities and the COVID-19 pandemic}

Finally, at time of writing, many legacy digital inequalities are being exacerbated by the COVID-19 pandemic in new ways (Robinson, et al., 2020). In particular, digital inequalities related to healthcare, education, economic disadvantage are even more pronounced. Regarding healthcare, Khilnani, et al. (2020) argue that "because the digitally disadvantaged are less likely to use eHealth services, they bear greater risks during the pandemic in order to meet ongoing medical care needs." Differentiated disadvantage also marks the experience of digitally 
disadvantaged students who cannot take advantage of remote learning via the Internet and who are at greater risk of falling behind their digitally resourced peers. In both the case of eHealth and eEducation, we see how economic advantage and digital advantage compound one another in light of the COVID-19 pandemic. While difficult for all, the digitally under-resourced are at greater risk and bear greater burdens than those who can mitigate the effects of the pandemic with digital resources.

\section{0: Implications of legacy digital inequalities}

Although 25 years have passed since the digital divide was first recognized, digital inequalities have become more multifaceted. As we have seen across these many thematic foci, the digital inequality stack encompasses access to connectivity networks, devices, and software, as well as collective access to network infrastructure. Other layers of the digital inequality stack include differentiated use and consumption, literacies and skills, production and programming, etc. Further, layers in the digital inequality stack are interconnected such that a deficiency in one layer may precipitate deficiencies in other layers. When inequality exists at foundational layers of the digital inequality stack (access to networks, devices, software), this translates into inequalities at higher levels including skill building and use for capital-enhancing activities.

When digital inequalities begin early in life, they impact educational and professional trajectories because all layers of the stack must work together to produce optimal outcomes. Digitally disadvantaged individuals cannot afford multiple personal devices or plentiful subscription software at home or for work. They are less likely to have been exposed to digital skills training at school or on the job. As skills may be implicated in usage, such individuals use digital resources for entertainment and leisure activities rather than work or capitalenhancing activities that might improve life chances. For the digitally disadvantaged, connectivity, device, software, skills, and usage gaps amplify one another. When layers in the digital inequality stack move in tandem with one another, all layers of the digital inequality stack reinforce disadvantage.

For example, we might consider the following digital inequality stack profile of "Alex," an individual for whom all stack layers are compromised. Alex lives in a rural area in a developed economy. Alex finished the minimal education required by the state but did not learn digital skills at school. As a customer associate in a large retail chain outlet, Alex does not engage any digital resources or skills acquisition training on the job. As an unskilled worker, Alex's low wages make consistent, quality home broadband, multiple personal devices, and subscription software unaffordable. Therefore, in parallel with others in Alex's family and social circles, Alex depends on an outdated smartphone with spotty reception for all digital activities, which are largely for social media or entertainment that is free-of-charge. For Alex, all layers of the digital inequality stack are reinforced by social networks and contacts that reinforce disadvantage. As this indicates, disruption to one layer of the digital inequality stack may damage the whole because when any layer in the stack is compromised, it may negatively affect the entirety of the stack.

Yet Alex's situation is largely rooted in socio-economic class disparities that are reinforced by education, rural residency, and social networks. As we have shown, equally salient forms of digital inequality include but are not limited to gender, sexuality, race and ethnicity, disability, aging, healthcare, and global disparities. All of these layers of the digital inequality stack magnify and amplify one another, particularly when combined with other forms of disadvantage. At the same time, the combination of these reinforcing forms of digital inequality serves to replicate social reproduction in multiple life realms. Digital inequalities, therefore, are reproduced through individuals' everyday experiences and embeddedness in different hierarchies. As we are increasingly aware of how digital inequalities are more interwoven with other disparities, we see that the main axes of social inequalities - inter alia those enumerated above - still influence and shape digital inequalities.

The multidimensionality and multi-layered nature of the digital inequality stack calls for a new interdisciplinary theoretical and empirical approach that takes into account not only these legacy inequalities but also emergent inequalities. Therefore, we take these arguments further in the second article in this two-part series, "Digital inequalities 3.0: Emergent inequalities in the information age." Across the two articles, we reject technodeterminism or market forces as solutions. Rather, as our work shows, social inequalities are strongly intertwined with digital inequalities; we cannot tackle digital inequalities in isolation from the social world that produces them. Concluding with our metaphor of the digital inequality stack, we reiterate how this multifaceted and multidimensional issue includes several layers that must be addressed together for our collective well-being. 


\section{About the authors}

Laura Robinson is Associate Professor in the Department of Sociology at Santa Clara University. She earned her Ph.D. from UCLA, where she held a Mellon Fellowship in Latin American Studies and received a Bourse d'Accueil at the École Normale Suprieure. Robinson has served as Visiting Assistant Professor at Cornell University and as Chair of CITAMS (2014-2015). Her research has earned awards from CITASA, AOIR, and NCA IICD. In addition to digital inequalities, Robinson's work explores interaction and identity work, as well as media in Brazil, France, and the U.S.

Direct comments to: laura [at] laurarobinson [dot] org

Jeremy Schulz is Researcher at the UC Berkeley Institute for the Study of Societal Issues and a Fellow at the Cambridge Institute. He has also served as an Affiliate at the UC San Diego Center for Research on Gender in the Professions and a Council Member of the ASA Section on Consumers and Consumption. Previously, he held an NSF funded postdoctoral fellowship at Cornell University after earning his Ph.D. at UC Berkeley. He has also done research and published in areas including digital sociology, theory, qualitative research methods, work and family, and consumption.

E-mail: jmschulz [at] berkeley [dot] edu

Grant Blank is Survey Research Fellow at the Oxford Internet Institute and Senior Research Fellow at Harris Manchester College, both University of Oxford. He received the William F. Ogburn Career Achievement award from the Communication, Information Technology and Media Sociology section of the American Sociological Association in 2015. This award recognizes a sustained body of research that has made an outstanding contribution to the advancement of knowledge in the area of sociology of communication, information technology and media sociology.

E-mail: grant [dot] blank [at] oii [dot] ox [dot] ac [dot] uk

Massimo Ragnedda (Ph.D.) is a Senior Lecturer in Mass Communication at Northumbria University, Newcastle, U.K. where he conducts research on the digital divide and social media. He is the co-vice chair of the Digital Divide Working Group (IAMCR) and co-convenor of NINSO (Northumbria Internet and Society Research Group). He has authored 12 books with his publications appearing in numerous peer-reviewed journals, and book chapters in English, Spanish, Italian, Portuguese and Russian texts. His books include: Digital capital: $A$ Bourdieusian perspective on the digital divide (with Maria Laura Ruiu), Emerald Publishing, 2020; Digital inclusion: An international comparative analysis (co-edited with Bruce Mutsvairo), Lexington Books 2018; Theorizing the digital divide (co-edited with G. Muschert), Routledge (2017); The third digital divide: A Weberian approach to digital inequalities (2017), Routledge; The digital divide: The Internet and social inequality in international perspective (co-edited with G. Muschert) (2013), Routledge.

E-mail: massimo [dot] ragnedda [at] northumbria [dot] ac [dot] uk

Hiroshi Ono (Ph.D., sociology, Chicago; Docent, Economics, Stockholm School of Economics) is Professor of Human Resources Management at Hitotsubashi University Business School and Affiliated Professor of Sociology at Texas A\&M University. He writes and speaks extensively on the relationships among motivation, happiness and productivity in the workplace, and the interplay between demographic change and labor market dynamics in Japan. His latest research focuses on Japan's work reform, especially on reducing work hours and increasing labor productivity.

E-mail: hono [at] ics [dot] hub [dot] hit-u [dot] ac [dot] jp

Bernie Hogan (Ph.D. Toronto, 2009) is a Senior Research Fellow at the OII and Research Associate at the Department of Sociology. With training in sociology and computer science, Hogan focuses on how social networks and social media can be designed to empower people to build stronger relationships and stronger communities. Hogan has published in a wide variety of venues, from peer-reviewed papers in sociology journals (such as Social Networks, City and Community, Bulletin of Science Technology and Society, and Field Methods).

E-mail: bernie [dot] hogan [at] oii [dot] ox [dot] ac [dot] uk

Gustavo S. Mesch is a Professor of Sociology and the Rector of the University of Haifa. His research interests are technology and society, social effects of new media, youth Internet culture, social networks online and off- 
line. He is currently studying patterns of cyber fraud scams, identity theft and the use of preventive measures, a study funded by the Ministry of Science and Technology of Israel. He has served as Chair of the ASA CITAMS section and Editor-in-Chief of the Sociological Focus, the official journal of the North Central Sociological Association (U.S.).

E-mail: gustavo [at] soc [dot] haifa [dot] ac [dot] il

Shelia R. Cotten is an MSU Foundation Professor and the Associate Chair for Research in the Department of Media and Information at Michigan State University. She holds Affiliate Professor positions in the Department of Sociology and the College of Engineering. Her research examines technology use across the life course and health, workforce, education, and social impacts of this use. She is a past Chair of CITAMS and has also won the William F. Ogburn Senior Career Award and the Public Sociology Award. Beginning 1 August 2020, she will be the Associate Vice President for Research Development and a Provost's Distinguished Professor at Clemson University.

E-mail: cotten [at] msu [dot] edu

Susan B. Kretchmer is Co-Founder and President of the not-for-profit Partnership for Progress on the Digital Divide (PPDD, http://www.ppdd.org), the only academic professional organization in the world focused solely on the digital divide and on connecting research to policy-making and practice to strategize actions and catalyze solutions to this pressing societal concern. She is also the Lead Organizer of the Partnership for Progress on the Digital International Conferences series.

E-mail: Susan [dot] Kretchmer [at] ppdd [dot] org

Timothy Hale, Ph.D., is a medical sociologist in the Department of Kinesiology and Community Health at the University of Illinois at Urbana-Champaign. Previously, he served as Research Fellow at Partners Center for Connected Health and Harvard Medical School. His main research interest is the impact of information and communication technologies (ICTS) on health care and health lifestyles. Prior to joining the Center, he was a postdoctoral fellow at the University of Alabama at Birmingham where he studied the social and psychological impacts of ICT, focusing primarily on youth and older adults. Hale was elected as a CITASA Council Member (2012-2014). His work has been published in Information, Communication \& Society; Computers and Human Behavior; Journal of Health Communication and American Behavioral Scientist.

E-mail: timhale [at] illinois [dot] edu

Tomasz Drabowicz is on the faculty at the University of Lodz where he is the Chair of the Department of Sociology of Social Structure and Social Change in the Faculty of Economics and Sociology. Dr. Drabowicz received his Ph.D. from the Department of Political and Social Sciences at the European University Institute. His research areas include social mobility and social stratification, sustainable development, digital inequalities, and new technologies and their impact on social life.

E-mail: tomasz [dot] drabowicz [at] uni [dot] lodz [dot] pl

Pu Yan is a Researcher at Oxford Internet Institute, University of Oxford. Her doctoral research focuses on the influence of the emerging ICTs on everyday information practices in rural and urban China, which employs a mixed methods approach that combines big data research and ethnographic study into the study of human information practices. In her 15-month fieldwork in a village and a factory in central China, she explored the adoption and domestication of ICTs in developing areas and studied how the Internet has influenced information-seeking in everyday life. Her research interests include digital divides, information-seeking practices on the Internet, mobile social media, and international comparative study of media systems.

E-mail: pu [dot] yan [at] oii [dot] ox [dot] ac [dot] uk

Barry Wellman directs the NetLab Network and is the former S.D. Clark Professor of Sociology at the University of Toronto. Prof. Wellman is a Fellow of the Royal Society of Canada. He founded the International Network for Social Network Analysis in 1976-1977. He is the Chair-Emeritus of both the Community and Information Technologies section and the Community and Urban Sociology section of the American Sociological Association. He has been a keynoter at conferences ranging from computer science to theology. He is the (co-)author of more than 200 articles that have been co-authored with more than 80 scholars, and is the (co-)editor of five books.

E-mail: wellman [at] chass [dot] utoronto [dot] ca 
Molly-Gloria Harper is a graduate student in the Ph.D. sociology program at Western. Harper's background includes a Bachelor's with honours and Master's degree from the University of Windsor in the field of criminology. Harper's research interests include youth, deviancy, criminology, social media, the role technology plays in society, cyberbullying, and notions of accountability.

E-mail: mharpe22 [at] uwo [dot] ca

Anabel Quan-Haase is Professor in the Department of Sociology and Faculty of Information and Media Studies at Western University in Canada. Anabel Quan-Haase's research interests lie in the area of computer-mediated communication, the networked society, social networks, and new media and social change. Her current research projects examine how young people use instant messaging, Facebook, mobile phones and other communication tools and what the social consequences are for their social relations, community, and social capital.

E-mail: aquan [at] uwo [dot] ca

Hopeton S. Dunn is Professor of Media and Communication in the Department of Media Studies at the University of Botswana and Senior Research Associate in the School of Communication, University ofJohannesburg, South Africa. Professor Dunn served as Director of the Caribbean School of Media and Communication at the University of the West Indies, Jamaica, where he remains Academic Director of the Mona ICT Policy Centre.

E-mail: hopetondunn [at] gmail [dot] com

Antonio A. Casilli is a professor of sociology at Telecom Paris, the telecommunication school of the Institut Polytechnique de Paris, and a researcher at the Interdisciplinary Institute on Innovation (i3). His research foci are digital labor, data governance, and human rights. He is the author of the award-winning book En attendant les robots (Editions du Seuil, 2019) and one of the co-creators of the documentary mini-series Invisibles (France Télévisions, 2020) about platform workers.

E-mail: antonio [dot] casilli [at] telecom-paris [dot] $\mathrm{fr}$

Paola Tubaro is Associate Research Professor at the National Centre for Scientific Research (CNRS, in French Centre National de la Recherche Scientifique). Tubaro is affiliated with the Laboratoire de Recherche en Informatique (CNRS, INRIA, and Université Paris-Saclay). At the crossroads of sociology, economics, and computer science, Tubaro's research explores the effects of big data and machine learning on markets, organizations, and labor. Her interests also include data methodologies and research ethics.

E-mail: paola [dot] tubaro [at] inria [dot] fr

Rod Carveth is an associate professor in strategic communication at the School of Global Journalism \& Communication at Morgan State University in Baltimore, Md. His research examines media economics and crisis communication. He is co-editor of the Media economics: Theory and practice (co-editor with Alison Alexander, James Owers, C. Ann Hollifield, and Albert N. Greco; third edition, Routledge, 2003; first edition, L. Erlbaum Associates, 1993; second edition, L. Erlbaum Associates, 1998) as well as over 45 book chapters and journal articles.

E-mail: rodcarveth [at] gmail [dot] com

Dr. Wenhong Chen is associate professor of media studies and sociology at the University of Texas at Austin. Her research has focused on digital media technologies in entrepreneurial and civic settings. Dr. Chen has more than 70 publications, including articles in top-ranked journals in the fields of communication and media studies, sociology, and management. Dr. Chen's research has received awards from the American Sociological Association, International Communication Association, and International Association of Chinese Management Research.

E-mail: wenhong [dot] chen [at] austin [dot] utexas [dot] edu

Julie B. Wiest is Associate Professor of Sociology at West Chester University of Pennsylvania. As a sociologist of culture and media, Wiest applies mainly symbolic interactionist and social constructionist perspectives to studies in three primary areas: the sociocultural context of violence, mass media effects, and the relationship between new media technologies and social change. Wiest's latest book, The allure of premeditated murder: Why some people plan to kill (2018, Rowman \& Littlefield), was co-authored with Jack Levin, who co-directs the Brudnick Center on Violence and Conflict at Northeastern University. 
E-mail: jwiest [at] wcupa [dot] edu

Matías Dodel olds a Ph.D. from the Department of Sociology, University of Haifa. He is an associate Professor of Communication at Universidad Católica del Uruguay. He is the director of the Internet of People (IoP) research group, where he coordinates the Uruguayan chapters of international comparative Internet studies such as World Internet Project, DiSTO (From Digital Skills to Tangible Outcomes), and Global Kids Online. His research interests are digital inequalities, social stratification, digital safety, and cybercrime.

E-mail: matias [dot] dodel [at] ucu [dot] edu [dot] uy

Michael J. Stern is Professor and Department Chairperson in the Department of Media + Information at Michigan State University. Stern has also served as the Director of the Web and Emerging Technologies Initiative and as a Senior Fellow at NORC at the University of Chicago. Substantively, his research focuses on theories of information seeking and digital inequality in the context of health, as well as the exclusion of marginalized and traditionally underrepresented groups in the areas of Internet usage, social media, and mobile emerging technologies.

E-mail: sternmi5 [at] msu [dot] edu

Christopher Ball is an assistant professor in the Department of Journalism at the University of Illinois at Urbana-Champaign. His research interests involve the influence of new technologies on society and how these technologies can be studied and harnessed for research, education, and outreach purposes. More specifically, his research focuses on the use of interactive media and technologies such as video games, virtual worlds, and virtual reality to foster pro-social outcomes and experiential learning across the life course.

E-mail: drball [at] illinois [dot] edu

Kuo-Ting Huang, Ph.D., is an assistant professor of Emerging Media Design \& Development in the Department of Journalism at Ball State University. His research focuses on the psychological, cognitive, and affective outcomes of interactive media usage, with an emphasis on digital games and virtual/augmented reality (VR/AR). Specifically, he is interested in how these psychological mechanisms can be harnessed to create virtual reality, augmented reality, and video game experiences that promote educational and health outcomes.

E-mail: khuang2 [at] bsu [dot] edu

Aneka Khilnani is currently a medical student at the George Washington University School of Medicine and Health Sciences in Washington, D.C. She completed a M.S. in physiology at Georgetown University, where she focused on preventative medicine and novel renal pharmacologics. She currently serves on the university's medical admissions committee and internal medicine board. She is also a representative for the American Association of Medical Colleges and actively conducts research in the Dermatology Department at Children's National Hospital. She has a special interest in telemedicine and digital inclusion. She has also served in numerous editorial positions, co-edited several volumes, and has published in the American Behavioral Scientist and Emerald Studies in Media and Communications.

E-mail: aneka [at] gwu [dot] edu

\section{Acknowledgements}

We thank Edward J. Valauskas, Chief Editor and Founder of First Monday, for the opportunity to publish our work thanks to the journal's pioneering provision of the open access publishing model. In the spirit of digital inclusion, we can think of no better venue to share our research. In addition, we thank the anonymous reviewers for their time and commentary, as well as Aneka Khilnani (Managing Editor) and Natalia Tolentino (Assistant Editor) for their exemplary work and service.

\section{Note}

1. The order of authors reflects the sequence of contributions to the two-part article series as follows.

"Digital inequalities 2.0: Emergent inequalities in the information age" was co-authored by: Laura Robinson and Jeremy Schulz (Legacy inequalities in the information age: The digital inequality stack); Grant Blank (From digital divides to digital inclusion); Massimo Ragnedda (Economic class); Hiroshi Ono (Gender); Bernie Hogan (Sexuality); Gustavo Mesch (Race and ethnicity); Shelia R. Cotten (Aging); Susan B. Kretchmer (Disability); 
Timothy M. Hale (Healthcare); Tomasz Drabowicz (Education); Pu Yan (Rural and urban inequalities); Barry Wellman and Molly-Gloria Harper (Networked individualism); Anabel Quan-Haase (Global digital inequality); Aneka Khilnani (Digital inequalities and COVID-19); and Jeremy Schulz, Laura Robinson, and Massimo Ragnedda (2.0: Implications of legacy digital inequalities).

"Digital inequalities 3.0: Legacy inequalities in the information age" was co-authored by Laura Robinson and Jeremy Schulz (Emergent inequalities in the information age); Hopeton S. Dunn (Accessibility as a human right); Antonio A. Casilli and Paola Tubaro (The platform economy and digital labor); Rod Carveth (Automation); Wenhong Chen (Big data and algorithms); Julie B. Wiest (Digital intersections with criminal justice and security); Matías Dodel (Cybersafety); Michael J. Stern (Civic engagement and mobility); Christopher Ball (Gaming); KuoTing Huang (Well-being and the life course);); Aneka Khilnani (Assistive technologies); Jeremy Schulz, Massimo Ragnedda, and Laura Robinson (3.0: Implications of emergent digital inequalities).

\section{References}

M. Aitken, B. Clancy, and D. Nass, 2017. "The growing value of digital health," IQVIA Institute (7 November), at https://www.iqvia.com/insights/the-iqvia-institute/reports/the-growing-value-of-digital-health, accessed 16 June 2020.

M. Anderson and M. Kumar, 2019. "Digital divide persists even as lower-income Americans make gains in tech adoption," Pew Research Center (7 May), at https://www.pewresearch.org/fact-tank/2019/05/07/digitaldivide-persists-even-as-lower-income-americans-make-gains-in-tech-adoption/, accessed 16 June 2020.

M. Anderson and A. Perrin, 2017. "Tech adoption climbs among older adults," Pew Research Center (17 May), at https://www.pewinternet.org/2017/05/17/tech-adoption-climbs-among-older-adults/, accessed 16 June 2020.

P. Attewell, 2001. "Comment: The first and second digital divides," Sociology of Education, volume 74, number 3, pp. 252-259. doi: https://doi.org/10.2307/2673277, accessed 16 June 2020.

C. Ball, K.-T. Huang, R.V. Rikard, and S.R. Cotten, 2019. "The emotional costs of computers: An expectancyvalue theory analysis of predominantly low-socioeconomic status minority students' STEM attitudes," Information, Communication \& Society, volume 22, number 1, pp. 105-128. doi: https://doi.org/10.1080/1369118X.2017.1355403, accessed 16 June 2020.

C. Ball, K.-T. Huang, S.R. Cotten, and R.V. Rikard, 2018. "Gaming the SySTEM: The relationship between video games and the digital and STEM divides," Games and Culture, volume 15, number 5, pp. 501-528. doi: https://doi.org/10.1177/1555412018812513, accessed 16 June 2020.

C. Ball, K.-T. Huang, S.R. Cotten, and R.V. Rikard, 2017. "Pressurizing the STEM pipeline: An expectancy-value theory analysis of youths' STEM attitudes," Journal of Science Education and Technology, volume 26, number 4, pp. 372-382. doi: https://doi.org/10.1007/s10956-017-9685-1, accessed 16 June 2020.

S. Bates, 2017. "Revenge porn and mental health: A qualitative analysis of the mental health effects of revenge porn on female survivors," Feminist Criminology, volume 12, number 1, pp. 22-42. doi: https://doi.org/10.1177/1557085116654565, accessed 16 June 2020.

M.H. Baturay and S. Toker, 2015. "An investigation of the impact of demographics on cyberloafing from an educational setting angle," Computers in Human Behavior, volume 50, number 1, pp. 358-366. doi: https://doi.org/10.1016/i.chb.2015.03.081, accessed 16 June 2020.

R.W. Berkowsky, R.V. Rikard, and S.R. Cotten, 2015. "Signing off: Predicting discontinued ICT usage among older adults in assisted and independent living: A survival analysis," In: J. Zhou and G. Salvendy (editors). Human aspects of IT for the aged population. Design for everyday life. Lecture Notes in Computer Science, volume 9194. Cham, Switzerland: Springer, pp. 389-398. doi: https://doi.org/10.1007/978-3-319-20913-5 36, accessed 16 June 2020.

T.P.G. Bertrand and J.M. Fidele, 2016. "Digital divides in Sub-Saharan Africa: Gender issues and evidence from Cameroon," African Review of Economics and Finance, volume 8, number 2, pp. 201-233, at https://www.ajol.info/index.php/aref/article/view/162161, accessed 16 June 2020. 
C. Blackwell, J. Birnholtz, and C. and Abbott, 2015. "Seeing and being seen: Co-situation and impression formation using Grindr, a location-aware gay dating app," New Media \& Society, volume 17, number 7, pp. 1,117-1,136. doi: https://doi.org/10.1177/1461444814521595, accessed 16 June 2020.

P. Blanck, 2014. "The struggle for Web eQuality by persons with cognitive disabilities," Behavioral Sciences \& the Law, volume 32, number 1, pp. 4-32. doi: https://doi.org/10.1002/bsl.2101, accessed 16 June 2020.

T. Boas, T. Dunning, and J. Bussell, 2005. "Will the digital revolution revolutionize development? Drawing together the debate," Studies in Comparative International Development, volume 40, number 2, pp. 95-110; version at https://gspp.berkeley.edu/research/selected-publications/will-the-digital-revolution-revolutionizedevelopment-drawing-together-the, accessed 16 June 2020.

H. Bonfadelli, 2002. "The Internet and knowledge gaps: A theoretical and empirical investigation," European Journal of Communication, volume 17, number 1, pp. 65-84. doi: https://doi.org/10.1177/0267323102017001607, accessed 16 June 2020.

P. Bourdieu, 1986. "The forms of capital," In: J. Richardson (editor). Handbook of theory and research for the sociology of education. New York: Greenwood, pp. 241-258.

E.E. Bruch and M.E.J. Newman, 2018. "Aspirational pursuit of mates in online dating markets," Science Advances, volume 4, number 8, eaap9815. doi: https://doi.org/10.1126/sciadv.aap9815, accessed 16 June 2020.

R.S. Burt, 2001. "Structural holes versus network closure as social capital," In: N. Lin, K.S. Cook, and R.S. Burt (editors). Social capital: Theory and research. New York: Aldine de Gruyter, pp. 31-55.

C. Campos-Castillo, 2015. "Revisiting the first-level digital divide in the United States: Gender and race/ethnicity patterns, 2007-2012," Social Science Computer Review, volume 33, number 4, pp. 423-439. doi: https://doi.org/10.1177/0894439314547617, accessed 16 June 2020.

M. Castells, 1996. The rise of the network society. Oxford: Blackwell.

W. Chen, 2013. "The implications of social capital for the digital divides in America," Information Society, volume 29, number 1, pp. 13-25. doi: https://doi.org/10.1080/01972243.2012.739265, accessed 16 June 2020.

W. Chen and B. Wellman, 2004. "The global digital divide - within and between countries," IT \& Society, volume 1 , number 7 , pp. 39-45.

C.-H. Chao and Y.-H. Tao, 2012. "Human flesh search: A supplemental review," Cyberpsychology, Behavior, and Social Networking, volume 15, number 7, pp. 350-356. doi: https://doi.org/10.1089/cyber.2011.0481, accessed 16 June 2020.

D.P. Cingel and E. Hargittai, 2018. "The relationship between childhood rules about technology use and laterlife academic achievement among young adults," Communication Review, volume 21, number 2, pp. $131-152$. doi: https://doi.org/10.1080/10714421.2018.1468182, accessed 16 June 2020.

S.R. Cotten, forthcoming. "Technologies and aging: Understanding use, impacts, and future needs," In: K.F. Ferraro and D. Carr.(editors). Handbook of aging and the social sciences. Ninth edition. New York: Elsevier.

S.R. Cotten, 2001. "Implications of Internet technology for medical sociology in the new millennium," Sociological Spectrum, volume 21, number 3, pp. 319-340. doi: https://doi.org/10.1080/027321701300202019, accessed 16 June 2020.

S.R. Cotten, E.A. Yost, R.W. Berkowsky, V. Winstead, and W.A. Anderson, 2017. Designing technology training for older adults in continuing care retirement communities. Boca Raton, Fla.: CRC Press.

S.R. Cotten and S.S. Gupta, 2004. "Characteristics of online and offline health information seekers and factors that discriminate between them," Social Science \& Medicine, volume 59, number 9, pp. 1,795-1,806. doi: https://doi.org/10.1016/j.socscimed.2004.02.020, accessed 16 June 2020.

P. DiMaggio and F. Garip, 2012. "Network effects and social inequality," Annual Review of Sociology, volume 38, pp. 93-118. doi: https://doi.org/10.1146/annurev.soc.012809.102545, accessed 16 June 2020.

P. DiMaggio, E. Hargittai, C. Celeste, and S. Shafer, 2004. “Digital inequality: From unequal access to differentiated use," In: K. Neckerman (editor). Social inequality. New York: Russell Sage Foundation, pp. 355400. 
T.A. DiPrete, A. Gelman, T. McCormick, J. Teitler, and T. Zheng, 2011. "Segregation in social networks based on acquaintanceship and trust," American Journal of Sociology, volume 116, number 4, pp. 1,234-1,283. doi: https://doi.org/10.1086/659100, accessed 16 June 2020.

C.M. Donner, 2016. "The gender gap and cybercrime: An examination of college students' online offending," Victims \& Offenders, volume 11, number 4, pp. 556-577. doi: https://doi.org/10.1080/15564886.2016.1173157, accessed 16 June 2020.

T. Drabowicz, 2017. "Social theory of Internet use: Corroboration or rejection among the digital natives? Correspondence analysis of adolescents in two societies," Computers \& Education, volume 105, pp. 57-67. doi: https://doi.org/10.1016/j.compedu.2016.10.004, accessed 16 June 2020.

T. Drabowicz, 2014. "Gender and digital usage inequality among adolescents: A comparative study of 39 countries," Computers \& Education, volume 74, pp. 98-111. doi: https://doi.org/10.1016/j.compedu.2014.01.016, accessed 16 June 2020.

S. Duguay, 2016. "'He has a way gayer Facebook than I do': Investigating sexual identity disclosure and context collapse on a social networking site," New Media \& Society, volume 18, number 6, pp. 891-907. doi: https://doi.org/10.1177/1461444814549930, accessed 16 June 2020.

W.H. Dutton, E.J. Helsper, M.T. Whitty, N. Li, J.G. Buckwalter, and E. Lee, 2009. "The role of the Internet in reconfiguring marriages: A cross-national study," Interpersona, volume 3, supplement 2, pp. 3-18. doi: https://doi.org/10.5964/ijpr.v3isupp2.73, accessed 16 June 2020.

R. Eynon, 2009. "Mapping the digital divide in Britain: Implications for learning and education," Learning, Media and Technology, volume 34, number 4, pp. 277-290. doi: https://doi.org/10.1080/17439880903345874, accessed 16 June 2020.

M.L. Fang, S.L. Canham, L. Battersby, J. Sixsmith, M. Wada, and A. Sixsmith, 2019. “Exploring privilege in the digital divide: Implications for theory, policy, and practice," Gerontologist, volume 59, number 1, pp. e1-e15. doi: https://doi.org/10.1093/geront/gny037, accessed 16 June 2020.

C.S. Fischer, 1982. To dwell among friends: Personal networks in town and city. Chicago: University of Chicago Press.

J. Francis, T. Kadylak, T.W. Makki, R.V. Rikard, and S.R. Cotten, 2018. "Catalyst to connection: When technical difficulties lead to social support for older adults," American Behavioral Scientist, volume 62, number 9, pp. 1,167-1,185. doi: https://doi.org/10.1177/0002764218773829, accessed 16 June 2020.

C. Fuchs and E. Horak, 2008. "Africa and the digital divide," Telematics and Informatics, volume 25, number 2, pp. 99-116. doi: https://doi.org/10.1016/j.tele.2006.06.004, accessed 16 June 2020.

I. Gershon, 2010. The breakup 2.0: Disconnecting over new media. Ithaca, N.Y.: Cornell University Press.

T.J. Gray, J. Gainous, and K.M. Wagner, 2017. "Gender and the digital divide in Latin America," Social Science Quarterly, volume 98, number 1, pp. 326-340. doi: https://doi.org/10.1111/ssqu.12270, accessed 16 June 2020.

J.C. Gulek and H. Demirtas, 2005. "Learning with technology: The impact of laptop use on student achievement," Journal of Technology, Learning and Assessment, volume 3, number 2, pp. 1-39, and at https://ejournals.bc.edu/index.php/itla/article/view/1655, accessed 16 June 2020.

T.M. Hale, W.-Y.S. Choi, and S.R. Cotten, 2018. eHealth: Current evidence, promises, perils and future directions. Studies in Media and Communications, volume 15. Bingley, West Yorkshire: Emerald Publishing.

T.M. Hale, M. Goldner, M. Stern, P. Drentea, and S.R. Cotten, 2014. "Patterns of online health searching 20022010: Implications for social capital, health disparities and the de-professionalization of medical knowledge," In: J.J. Kronenfeld (editor). Technology, communication, disparities and government options in health and health care services. Research in the sociology of health care, volume 32, Bingley, West Yorkshire: Emerald Publishing pp. 35-60. doi: https://doi.org/10.1108/S0275-495920140000032016, accessed 16 June 2020.

R. Hämäläinen, B. De Wever, A. Malin, and S. Cincinnato, 2015. "Education and working life: VET adults' problem-solving skills in technology-rich environments," Computers \& Education, volume 88, pp. 38-47. doi: https://doi.org/10.1016/j.compedu.2015.04.013, accessed 16 June 2020. 
K.N. Hampton and B. Wellman, 2018. "Lost and saved... again: The moral panic about the loss of community takes hold of social media," Contemporary Sociology, volume 47, number 6, pp. 643-651. doi: https://doi.org/10.1177/0094306118805415, accessed 16 June 2020.

E.J. Helsper, 2014. “Offline social identity and online chat partner selection," Information, Communication \& Society, volume 17, number 6, pp. 695-715. doi: https://doi.org/10.1080/1369118X.2013.810767, accessed 16 June 2020.

J. Henry, Y. Pylypchuck, T. Searcy, and V. Patel, 2016. "Adoption of electronic health record systems among U.S. non-federal acute care hospitals: 2008-2015," ONC Data Brief, number 35, at https://www.healthit.gov/sites/default/files/briefs/2015 hospital_adoption_db_v17.pdf, accessed 16 June 2020.

D.L. Hoffman and T.P. Novak, 1998. "Bridging the racial divide on the Internet," Science, volume 280, number 5362 (17 April), pp. 390-391. doi: https://doi.org/10.1126/science.280.5362.390, accessed 16 June 2020.

B. Hogan, 2018. "Break-ups and the limits of encoding love," In: Z. Papacharissi (editor). A networked self and love. New York: Routledge, pp. 113-128.

M.R. Hoque, Y. Bao, and G. Sorwar, 2017. "Investigating factors influencing the adoption of e-Health in developing countries: A patient's perspective," Informatics for Health and Social Care, volume 42, number 1, pp. 13-17. doi: https://doi.org/10.3109/17538157.2015.1075541, accessed 16 June 2020.

K.-T. Huang, L. Robinson, and S.R. Cotten, 2015. "Mind the emotional gap: The impact of emotional costs on student learning outcomes," Communication and Information Technologies Annual>, volume 10, pp. 121-144. doi: https://doi.org/10.1108/S2050-206020150000010005, accessed 16 June 2020.

L.A. Jackson, Y. Zhao, Y., A. Kolenic III,, H.E. Fitzgerald, R. Harold, and A. Von Eye, 2008. "Race, gender, and information technology use: The new digital divide," CyberPsychology \& Behavior, volume 11, number 4, pp. 437-442. doi: https://doi.org/10.1089/cpb.2007.0157, accessed 16 June 2020.

P.T. Jaeger, 2011. Disability and the Internet: Confronting a digital divide. Boulder, Colo.: Lynne Rienner Publishers.

H. Jenkins, K. Clinton, R. Purushotma, A.J. Robison, and M. Weigel, 2006. "Confronting the challenges of participatory culture: Media education for the 21st century," John D. and Catherine T. MacArthur Foundation, at http://www.newmedialiteracies.org, accessed 16 June 2020.

M. Jiang, H.S. Tsai, S.R. Cotten, N.J. Rifon, R. LaRose, and S. Alhabash, 2016. “Generational differences in online safety perceptions, knowledge, and practices," Journal of Educational Gerontology, volume 42, number 9, pp. 621-634. doi: https://doi.org/10.1080/03601277.2016.1205408, accessed 16 June 2020.

S. Judge, 2005. "The impact of computer technology on academic achievement of young African American children," Journal of Research in Childhood Education, volume 20, number 2, pp. 91-101. doi: https://doi.org/10.1080/02568540509594554, accessed 16 June 2020.

S. Judge, K. Puckett, and S.M. Bell, 2006. "Closing the digital divide: Update from the early childhood longitudinal study," Journal of Educational Research, volume 100, number 1, pp. 52-60. doi: https://doi.org/10.3200/JOER.100.1.52-60, accessed 16 June 2020.

R. Junco and S.R. Cotten, 2012. "No A 4 U: The relationship between multitasking and academic performance," Computers \& Education, volume 59, number 2, pp. 505-514. doi: https://doi.org/10.1016/j.compedu.2011.12.023, accessed 16 June 2020.

R. Junco and S.R. Cotten, 2011. "Perceived academic effects of instant messaging use," Computers \& Education, volume 56, number 2, pp. 370-378. doi: https://doi.org/10.1016/j.compedu.2010.08.020, accessed 16 June 2020.

B. Kannan, S. Karthik, G.K. Pal, and V. Menon, 2019. "Gender variation in the prevalence of Internet addiction and impact of Internet addiction on reaction time and heart rate variability in medical college students," Journal of Clinical \& Diagnostic Research, volume 13, number 4, pp. 1-4.

J. Katz and P. Aspden, 1997. "Motivations for and barriers to Internet usage: Results of a national public opinion survey," Internet Research, volume 7, number 3, pp. 170-188. doi: https://doi.org/10.1108/10662249710171814, accessed 16 June 2020. 
A. Khilnani, J. Schulz, and L. Robinson, 2020. "The COVID-19 pandemic: New concerns and connections between eHealth and digital inequalities," Journal of Information, Communication \& Ethics in Society. doi: https://doi.org/10.1108/JICES-04-2020-0052, accessed 16 June 2020.

S.B. Kretchmer and T. Drabowicz, 2018. "Exploring the disability digital divide: Research that impacts interventions through policy and practice," In: A. Shaw and D.T. Scott (editors). Interventions: Communication research and practice. New York: Peter Lang, pp. 143-166. doi: https://doi.org/10.3726/b13081, accessed 16 June 2020.

J. Kvedar, M.J. Coye, and W. Everett, 2014. "Connected health: a review of technologies and strategies to improve patient care with telemedicine and telehealth," Health Affairs, volume 33, number 2, pp. 194-199. doi: https://doi.org/10.1377/hlthaff.2013.0992, accessed 16 June 2020.

K. Latulippe, C. Hamel, and D. Giroux, 2017. "Social health inequalities and eHealth: A literature review with qualitative synthesis of theoretical and empirical studies," Journal of Medical Internet Research, volume 19, number 4, e136. doi: https://doi.org/10.2196/jmir.6731, accessed 16 June 2020.

J. LaViolette and B. Hogan, 2019. “Using platform signals for distinguishing discourses: The case of men's rights and men's liberation on Reddit," Proceedings of the Thirteenth International AAAl Conference on Web and Social Media, volume 13, pp. 323-334, and at https://www.aaai.org/ojs/index.php/ICWSM/article/view/3357, accessed 16 June 2020.

J. Lei and Y. Zhao, 2007. "Technology uses and student achievement: A longitudinal study," Computers \& Education, volume 49, number 2, pp. 284-296. doi: https://doi.org/10.1016/j.compedu.2005.06.013, accessed 16 June 2020 .

R. Ling and H.A. Horst, 2011. "Mobile communication in the global south," New Media \& Society, volume 13, number 3, pp. 363-374. doi: https://doi.org/10.1177/1461444810393899, accessed 16 June 2020.

S. Livingstone, G. Mascheroni, and E. Staksrud, 2018. "European research on childrens Internet use: Assessing the past and anticipating the future," New Media \& Society, volume 20, number 3, pp. 1,103-1,122. doi: https://doi.org/10.1177/1461444816685930https://doi.org/10.1177/1461444816685930, accessed 16 June 2020.

M.P. Mahoney, 2010. "Students' attitudes toward STEM: Development of an instrument for high school STEMbased programs," Journal of Technology Studies, volume 36, number 1, pp. 24-34.

E. McConnell, B. Néray, B. Hogan, A. Korpak, A. Clifford, and M. Birkett, 2018. “'Everybody puts their whole life on Facebook': Identity management and the online social networks of LGBTQ youth," International Journal of Environmental Research and Public Health, volume 15, number 6, 1078. doi: https://doi.org/10.3390/ijerph15061078, accessed 16 June 2020.

B. McNair, 2013. Porno? Chic! How pornography changed the world and made it a better place. New York: Routledge.

R.K. Merton, 1968. "The Matthew effect in science: The reward and communication systems of science are considered," Science, volume 159, number 3810 (5 January), pp. 56-63. doi: https://doi.org/10.1126/science.159.3810.56, accessed 16 June 2020.

G.S. Mesch, 2018. "Race, ethnicity and the strength of Facebook ties," Journal of Youth Studies, volume 21, number 5, pp. 575-589. doi: https://doi.org/10.1080/13676261.2017.1396303, accessed 16 June 2020.

G.S. Mesch, 2016. "Ethnic origin and access to electronic health services," Health Informatics Journal, volume 22, number 4, pp. 791-803. doi: https://doi.org/10.1177/1460458215590863, accessed 16 June 2020.

G. Mesch, R. Mano, and J. Tsamir, 2012. "Minority status and health information search: A test of the social diversification hypothesis," Social Science \& Medicine, volume 75, number 5, pp. 854-858. doi: https://doi.org/10.1016/i.socscimed.2012.03.024, accessed 16 June 2020.

U.A. Mitchell, P.G. Chebli, L. Ruggiero, and N. Muramatsu, 2019. "The digital divide in health-related technology use: The significance of race/ethnicity," Gerontologist, volume 59, number 1, pp. 6-14. doi: https://doi.org/10.1093/geront/gny138, accessed 16 June 2020. 
D. Mok, B. Wellman, and J. Carrasco, 2010. “Does distance matter in the age of the Internet?" Urban Studies, volume 47, number 13, pp. 2,747-2,783. doi: https://doi.org/10.1177/0042098010377363, accessed 16 June 2020.

S. Moller, N. Banerjee, M.C. Bottia, E. Stearns, R.A. Mickelson, M. Dancy, and L. Valentino, 2015. “Moving Latino/a students into STEM majors in college: The role of teachers and professional communities in secondary schools," Journal of Hispanic Higher Education, volume 14, number 1, pp. 3-33. doi: https://doi.org/10.1177/1538192714540533, accessed 16 June 2020.

E.M. Morgan, 2011. "Associations between young adults' use of sexually explicit materials and their sexual preferences, behaviors, and satisfaction," Journal of Sex Research, volume 48, number 6, pp. 520-530. doi: https://doi.org/10.1080/00224499.2010.543960, accessed 16 June 2020.

D. Nemer, 2015. "From digital divide to digital inclusion and beyond," Journal of Community Informatics, volume 11, number 1, at http://ci-journal.net/index.php/ciej/article/view/1030, accessed 16 June 2020.

G. Nimrod, 2018. "Technostress: Measuring a new threat to well-being in later life," Aging \& Mental Health, volume 22, number 8, pp. 1,086-1,093. doi: https://doi.org/10.1080/13607863.2017.1334037, accessed 16 June 2020 .

P. Norris, 2001. Digital divide: Civic engagement, information poverty, and the Internet worldwide. New York: Cambridge University Press.

A.M. Norton, J. Baptist, and B. Hogan, 2018. "Computermediated communication in intimate relationships: Associations of boundary crossing, intrusion, relationship satisfaction, and partner responsiveness," Journal of Marital and Family Therapy, volume 44, number 1, pp. 165-182. doi: https://doi.org/10.1111/jmft.12246, accessed 16 June 2020.

E. Oreglia, 2015. "The 'sent-down' Internet: Using information and communication technologies in rural China," Chinese Journal of Communication, volume 8 , number 1 , pp. 1-6. doi: https://doi.org/10.1080/17544750.2015.991369, accessed 16 June 2020.

E. Oreglia, 2013. "From farm to Farmville: Circulation, adoption, and use of ICT between urban and rural China," Ph.D. dissertation, University of California, Berkeley, at https://escholarship.org/uc/item/68s0x1r3, accessed 16 June 2020 .

Organisation for Economic Cooperation and Development (OECD), 2018. "Bridging the digital gender divide: Include, upskill, innovate," at http://www.oecd.org/internet/bridging-the-digital-gender-divide.pdf, accessed 16 June 2020

H. Ono and M. Zavodny, 2007. "Digital inequality: A five country comparison using microdata," Social Science Research, volume 36, number 3, pp. 1,135-1,155. doi: https://doi.org/10.1016/j.ssresearch.2006.09.001, accessed 16 June 2020.

H. Ono and M. Zavodny, 2003. "Gender and the Internet," Social Science Quarterly, volume 84, number 1, pp. 111-121. doi: https://doi.org/10.1111/1540-6237.t01-1-8401007, accessed 16 June 2020.

E.J. Pérez-Stable, B. Jean-Francois, and C.F. Aklin, 2019. "Leveraging advances in technology to promote health equity," Medical Care, volume 57, pp. S101-S103. doi: https://doi.org/10.1097/MLR.0000000000001112, accessed 16 June 2020.

J. Peter and P.M. Valkenburg, 2006. "Adolescents' exposure to sexually explicit material on the Internet," Communication Research, volume 33, number 2, pp. 178-204. doi: https://doi.org/10.1177/0093650205285369, accessed 16 June 2020.

J.C. Phelan, B.G. Link, and P. Tehranifar, 2010. "Social conditions as fundamental causes of health inequalities: Theory, evidence, and policy implications," Journal of Health and Social Behavior, volume 51, supplement 1, pp. S28-S40. doi: https://doi.org/10.1177/0022146510383498, accessed 16 June 2020.

A. Quan-Haase, H. Wang, B. Wellman, and A. Zhang, 2018. "Weaving family connections on and offline: The turn to networked individualism," In: B.B. Neves and C. Casimiro (editors). Connecting families? Information \& communication technologies, generations, and The life course. Bristol: Policy Press University of Bristol, pp. 5777. doi: https://doi.org/10.1332/policypress/9781447339946.003.0004, accessed 16 June 2020. 
D. Radcliffe, 2018. “Mobile in sub-Saharan Africa: Can world's fastest-growing mobile region keep it up?" ZDNet (16 October), at https://www.zdnet.com/article/mobile-in-sub-saharan-africa-can-worlds-fastest-growingmobile-region-keep-it-up/, accessed 16 June 2020.

M. Ragnedda, 2018. "Conceptualizing digital capital," Telematics and Informatics, volume 35, number 8, pp. 2,366-2,375. doi: https://doi.org/10.1016/j.tele.2018.10.006, accessed 16 June 2020.

M. Ragnedda, 2017. The third digital divide: A Weberian approach to digital inequalities. New York: Routledge.

M. Ragnedda and G.W. Muschert (editors), 2013. The digital divide: The Internet and social inequality in international perspective. New York: Routledge.

M. Ragnedda, M.L. Ruiu, and F. Addeo, 2020. "Measuring digital capital: An empirical investigation," New Media \& Society, volume 22, number 5, pp. 793-816. doi: https://doi.org/10.1177/1461444819869604, accessed 16 June 2020 .

L. Rainie and B. Wellman, 2012. Networked: The new social operating system. Cambridge, Mass.: MIT Press.

L. Robinson, 2020. "The STEM selfing process: Nondigital and digital determinants of aspirational STEM futures," American Behavioral Scientist (4 June). doi: https://doi.org/10.1177/0002764220919150, accessed 16 June 2020

L. Robinson, 2012. "Information-seeking 2.0: The effects of informational advantage," RESET: Recherches en Sciences Sociales sur Internet, at https://journals.openedition.org/reset/135, accessed 16 June 2020. doi: https://doi.org/10.4000/reset.135, accessed 16 June 2020.

L. Robinson and J. Schulz, 2013. "Net time negotiations within the family," Information, Communication \& Society, volume 16, number 4, pp. 542-560. doi: https://doi.org/10.1080/1369118X.2013.777761, accessed 16 June 2020

L. Robinson, $\varnothing$. Wiborg, and J. Schulz, 2018. "Interlocking inequalities: Digital stratification meets academic stratification," American Behavioral Scientist, volume 62, number 9, pp. 1,251-1,272. doi: https://doi.org/10.1177/0002764218773826, accessed 16 June 2020.

L. Robinson, J. Schulz, M. Dodel, T. Correa, E. Villanueva-Mansilla, S. Leal, C. Magallanes-Blanco, L. RodriguezMedina, H.S. Dunn, L. Levine, R. McMahon, and A. Khilnani, 2020. "Digital inclusion across the Americas and Caribbean," Social Inclusion, volume 8, number 2, pp. 244-259. doi: http://dx.doi.org/10.17645/si.v8i2.2632, accessed 16 June 2020.

A. Rosenmann and M.P. Safir, 2006. "Forced online: Push factors of Internet sexuality: A preliminary study of online paraphilic empowerment," Journal of Homosexuality, volume 51, number 3, pp. 71-92. doi: https://doi.org/10.1300/J082v51n03 05, accessed 16 June 2020.

N. Selwyn, 2005. "The social processes of learning to use computers," Social Science Computer Review, volume 23, number 1, pp. 122-135. doi: https://doi.org/10.1177/0894439304271553, accessed 16 June 2020.

Ł. Szulc and A. Dhoest, 2013. "The Internet and sexual identity formation: Comparing Internet use before and after coming out," Communications, volume 38, number 4, pp. 347-365. doi: https://doi.org/10.1515/commun-2013-0021, accessed 16 June 2020.

S. Taipale, 2013. "The relationship between Internet use, online and printed newspaper reading in Finland: Investigating the direct and moderating effects of gender," European Journal of Communication, volume 28, number 1, pp. 5-18. doi: https://doi.org/10.1177/0267323112453672, accessed 16 June 2020.

M. Tarafdar, Q. Tu, B.S. Ragu-Nathan, and T.S. Ragu-Nathan, 2007. "The impact of technostress on role stress and productivity," Journal of Management Information Systems, volume 24, number 1, pp. 301-328. doi: https://doi.org/10.2753/MIS0742-1222240109, accessed 16 June 2020.

P.J. Tichenor, G.A. Donohue, and C.N. Olien, 1970. "Mass media flow and differential growth in knowledge," Public Opinion Quarterly, volume 34, number 2, pp. 159-170. doi: https://doi.org/10.1086/267786, accessed 16 June 2020.

U.S. Census Bureau, 2001-2017. "Current population survey," at https://www.census.gov/programssurveys/cps.html, accessed 16 June 2020. 
A.J.A.M. van Deursen and J.A.G.M. van Dijk, 2019. "The first-level digital divide shifts from inequalities in physical access to inequalities in material access," New Media \& Society, volume 21, number 2, pp. 354-375. doi: https://doi.org/10.1177/1461444818797082, accessed 16 June 2020.

A.J.A.M. van Deursen and E.J. Helsper, 2015. "The third-level digital divide: Who benefits most from being online?" Communication and Information Technologies Annual, volume 10, pp. 29-52. doi: https://doi.org/10.1108/S2050-206020150000010002, accessed 16 June 2020.

A.J.A.M. van Deursen and J.A.G.M. van Dijk, 2014. "The digital divide shifts to differences in usage," New Media \& Society, volume 16, number 3, pp. 507-526. doi: https://doi.org/10.1177/1461444813487959, accessed 16 June 2020.

World Bank, 2020. "Disability inclusion" (15 May), at https://www.worldbank.org/en/topic/disability, accessed 16 June 2020. 